\title{
MEASUREMENT AND ANALYSIS OF GAIT BY USING A TIME-OF-FLIGHT CAMERA
}

\author{
C. Altuntas *, F. Turkmen, A. Ucar, Y. A. Akgul \\ Selcuk University, Engineering Faculty, Department of Geomatics, Alaeddin Keykubat Kampüsü, 42075 Selcuklu, Turkey - \\ caltuntas@selcuk.edu.tr
}

\section{Commission III, WG III/3}

KEY WORDS: Human Motion, Measurement, Time-of-Flight Camera, Mobile Measurement, Three-Dimensional, Range Imaging Camera

\begin{abstract}
:
Biomedical applications generally needs measurement the human body parts in motion. On the other hand, the analysis of the human motion includes mobile measurements. The mobile measurement is complicated task because it needs two or more sensor combination, specific measurement techniques and huge computation. Thus, it is actual research topic in photogrammetry and computer sciences community. Time-of-flight (ToF) camera can make measurement the moving object. It can be used for robotic and simultaneous localization and mapping applications. Human motion capture is recent application area for ToF camera. In this study analysis of the body motion were made with time-of-flight camera. We made measurement to runner on treadmill. The motion was analysed with computing the angle between body parts.
\end{abstract}

\section{INTRODUCTION}

Time-of-flight (ToF) camera has active optical measurement system. It is emerging technology for three-dimensional (3-D) measurement, motion detection, mobile measurement and robotic applications. New application areas and data processing techniques have been introduced by using ToF cameras in photogrammetry and engineering measurements. Oggier et al. (2005) investigated the measurement principle of ToF cameras. They showed that the ToF camera can be used in many measurement tasks instead of photogrammetry and laser scanning. Jamtsho (2010) used ToF camera for measurement of structural deformation. Piatti (2010) tested PMD CamCube3 and SR4000 cameras and 3D modelling task was performed by the cameras. Additionaly, Altuntas and Yildiz (2013), Jamtsho (2010), Boehm and Pattinson (2010) and Cui et al. (2010) used the cameras for 3-D modelling.

There are many study related to use of ToF camera in mobile and robotic applications. Clemente et al. (2007) made measurement while the camera is being moved by hand. The consecutive frames were registered into the reference system using detected features from the images. A similar study was also performed by Pirker et al. (2010). The robotic applications were carried out in the study of Cazorla et al. (2010) and Frank et al. (2010). On their study the object on field of view of the mobile robot was detected by the camera. Unexpected motion of the workers on construction site was also detected with continuously imaged the field of view by ToF camera (Teizer, 2008). Lichti et al. (2012) made structural deformation measurements under different loading environments. On the further study, real time hand motion tracking and the American sign language alphabet recognition was given at Lahamy and Lichti (2011) and Lahamy and Lichti (2012) respectively. Wide variety of applications which has been performed by the camera can be found on literature (Breuer et al., 2007; Hussmann et al. 2008).

Detection of human motion is active research area in computer vision. A number of significant research are identified together with novel methodologies for automatic initialization, tracking, pose estimation, movement recognition and etc. (Moeslund et al., 2006). On the other hand, in medical applications, specialists generally need definition positions of the body parts during the movement for designing the medical apparatus for disabled persons. Palagemann et al. (2010) and Ganapathi et al. (2010) identified the body parts in depth images at video frame rates. The orientation of body parts were estimated from 3D orientation vector for a given interest point. In this study, the motion of runner on treadmill was recorded by SR4000 ToF camera. The angles between the body parts were estimated and changing between them during the movement was analyzed.

\section{TIME-OF-FLIGHT CAMERA}

ToF camera measures distances between pixels and their corresponding object points. The measurement data are range from pixel to object point. The 3-D coordinates are computed from them according to local camera coordinate frame, which has $\mathrm{X}, \mathrm{Y}$ axis joined to front plane while the origin is on the optical axis (Figure 1). SR4000 camera has $144 \times 176$ pixel array and the object points correspond to the pixels are measured instantly. Moreover this measurement can be repeated 50 times for per second. Thanks to the measurement technique and light weight, it can be used for mobile measurement in case of motion the camera or object. In addition, ToF camera records intensity of laser beam reflected from the object surfaces for every pixel. Its measurement range is reach to $5 \mathrm{~m}$.

The measurement accuracy of ToF camera depends many effects such as illumination, surface reflectivity, range, temperature and integration time (Altuntas, 2014; Beringe, 2012). Kahlman et al. (2006) investigated the accuracy depended on temperature arising from environmental and interior of the instrument. In addition, the same study carried out a few millimetre differences between the distances measured by total station and the camera. The warm-up time of the camera was investigated on Piatti and Rinaudo (2012). Jamtsho (2010) was investigated accuracy of the ToF camera, and measured the structural deformation with $0.3 \mathrm{~mm}$ accuracy.

* Corresponding author 
The measurement accuracy of SR4000 is about $2 \mathrm{~cm}$ at maximum distance. On the other hand, multipath reflections on a concave scene cause error on the distances (Mesa Imaging, 2012).

The calibration of the camera is performed by special measurement configuration on test field (Lichti and Qi, 2012; Shahbazi et al., 2011). The distortion effect is eliminated from the measurement by the factory settings on SR4000 camera. Some technical specifications of SR4000 camera are given on Table 1 .

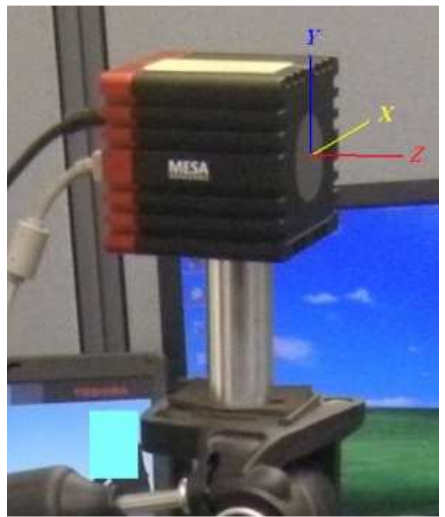

Figure 1. SR4000 camera (Altuntas, 2014)

\begin{tabular}{|l|l|}
\hline Company & Mesa Imaging \\
\hline Model & SR4000 \\
\hline Field of view & $43^{\circ}(\mathrm{H}) \times 34^{\circ}(\mathrm{V})$ \\
\hline Pixel array size & $176(\mathrm{H}) \times 144(\mathrm{~V})$ \\
\hline Detection range & $0.1 \mathrm{~m}-5 \mathrm{~m}$ \\
\hline Focal length & $10.0 \mathrm{~mm}$ \\
\hline Absolute accuracy & $+/-10 \mathrm{~mm}$ or $+/-1 \%$ \\
\hline Pixel pitch & $40 \mu \mathrm{m}$ \\
\hline Angular resolution & $\begin{array}{l}0.24^{\circ} \text { standard field of view } \\
\text { cameras }\end{array}$ \\
\hline Illumination wavelength & $850 \mathrm{~nm}$ \\
\hline $\begin{array}{l}\text { Modulation frequency } \\
\text { selection }\end{array}$ & $29 / 30 / 31 \mathrm{MHz}$ \\
\hline Integration time & $\begin{array}{l}0.3 \text { to } 25.8 \mathrm{~ms}, \text { steps of } 0.1 \\
\mathrm{~ms}\end{array}$ \\
\hline Operating temperature & $+10^{\circ} \mathrm{C}$ to $+50^{\circ} \mathrm{C}$ \\
\hline Maximum frame rate & $50 \mathrm{fps}$ \\
\hline Weight & $470 \mathrm{gr}$ for USB cameras \\
\hline Dimensions & $65 \times 65 \times 68 \mathrm{~mm}$ \\
\hline Connection & $\mathrm{USB}$ \\
\hline
\end{tabular}

Table 1. Some specifications of used SR4000 camera (url-1)

\section{METHODS}

\subsection{Motion Measurement}

Range data sequences acquired by a 3-D camera suffer from a substantial amount of noise. This noise can be reduced by employing temporal filtering of a large number of frames (Matzka et al., 2007). But we did not use filter in this study. Because characterised points of the body parts is enough to computing angles between them. Nevertheless points were signalized on characteristic place of the body (Figure 2). The angles on intersection of the body parts can be computed from 3-D coordinates that has been extracted from the successive images of ToF camera. Thus, successive frames must be recorded by the camera during the motion periods. In this study motion of runner on treadmill was measured and analysed. The camera was set one meter away from side of the treadmill for recording the motion (Figure 3). On the other hand, this task can be performed for runner on the way by measuring the images in mobile position of the camera.

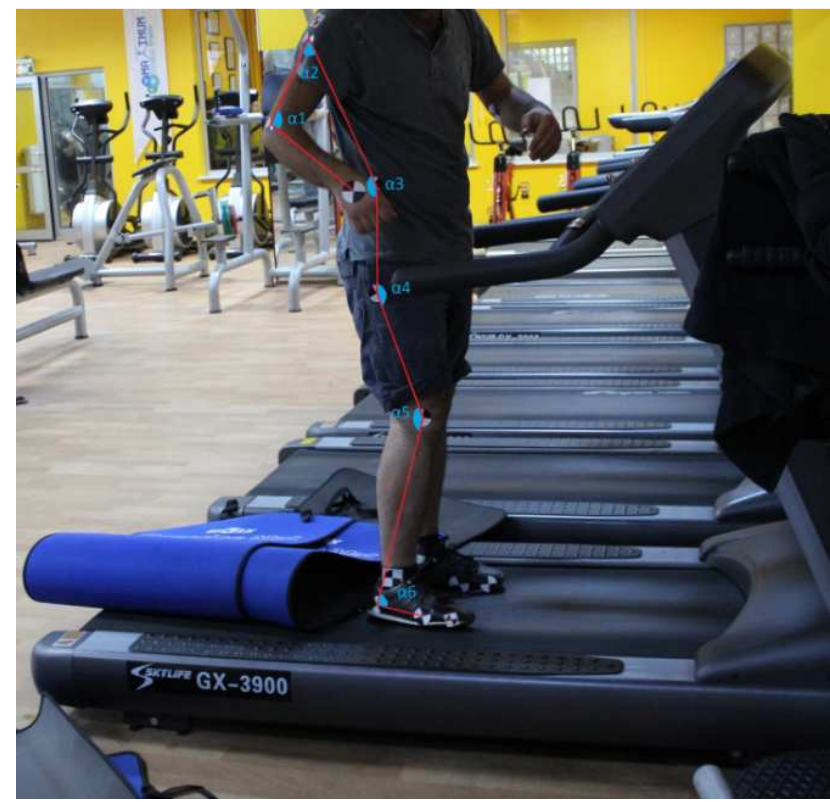

Figure 2. The measurement side

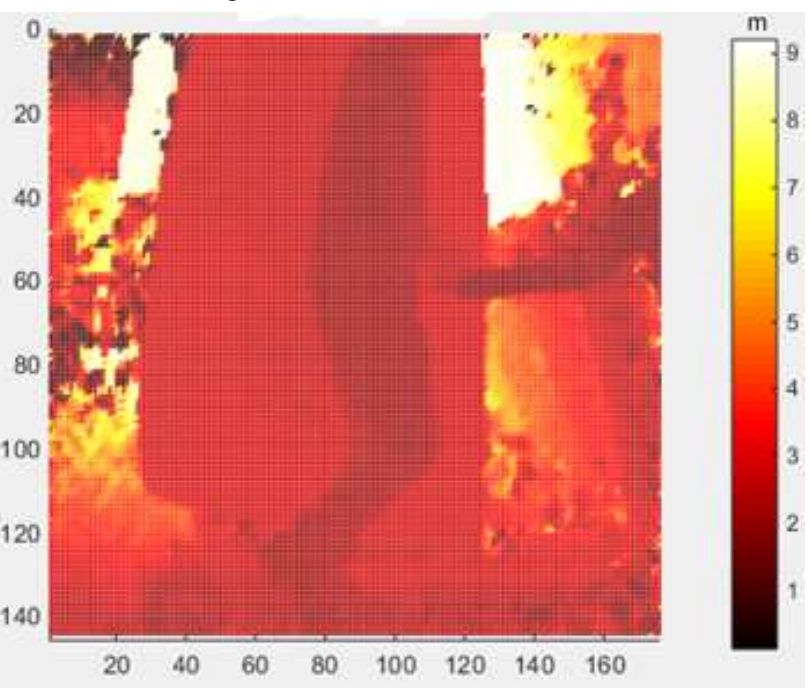

Figure 3. Depth image [legend unit is meter]

\subsection{Computation of the Angles}

The proper one has to be selected from consecutive frames to compute the angles at each position. After successive images, which have cover one period of the motion, were selected, intensity images were created for each one. Targets were selected from the intensity images and then we got their 3-D coordinates from the measurement data of the frames. The angle at intersection of body parts were computed in 3-D space (Figure 4). 


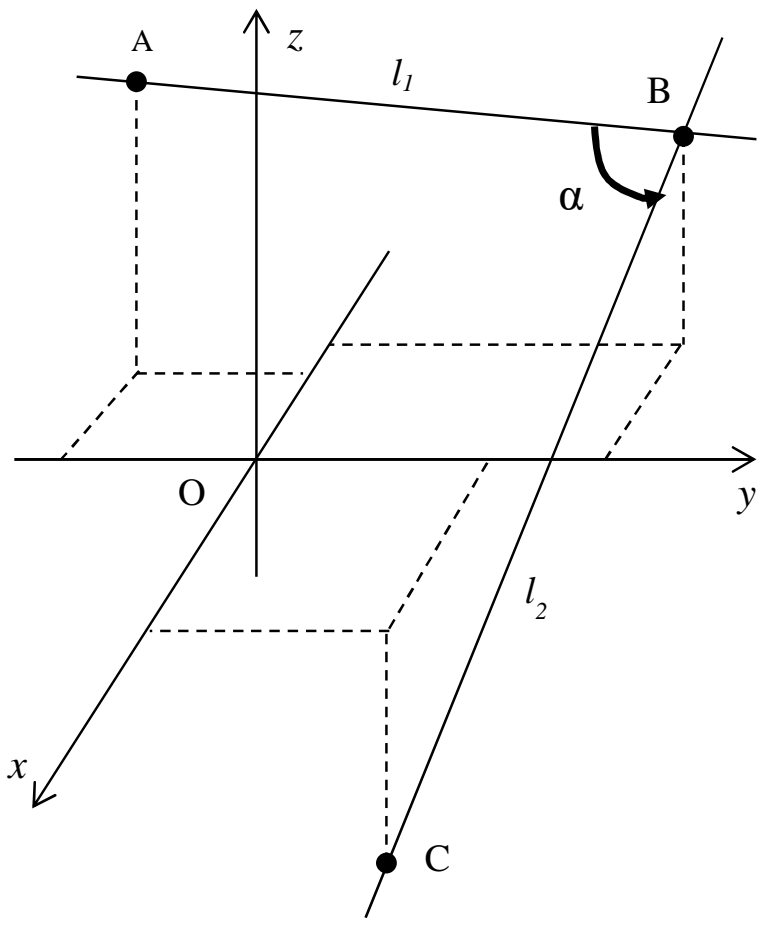

Figure 4. Angle $(\alpha)$ between lines $l_{l}$ and $l_{2}$ in 3-D space

The equation of a line $\left(l_{l}\right)$ passing through the point $\mathrm{A}\left(x_{1}, y_{1}, z_{1}\right)$ and $\mathrm{B}\left(x_{2}, y_{2}, z_{2}\right)$ is given by Equations (1) and (2) (Figure 4)

$$
\begin{aligned}
\frac{x-x_{1}}{x_{2}-x_{1}} & =\frac{y-y_{1}}{y_{2}-y_{1}}=\frac{z-z_{1}}{z_{2}-z_{1}} \\
\frac{x-x_{1}}{a_{1}} & =\frac{y-y_{1}}{b_{1}}=\frac{z-z_{1}}{c_{1}}
\end{aligned}
$$

Similarly, equation of a line $\left(l_{2}\right)$ passing through $\mathrm{B}\left(x_{2}, y_{2}, z_{2}\right)$ and $\mathrm{C}\left(x_{3}, y_{3}, z_{3}\right)$ is given (3)

$$
\frac{x-x_{2}}{a_{2}}=\frac{y-y_{2}}{b_{2}}=\frac{z-z_{2}}{c_{2}}
$$

Thus, the angle $(\alpha)$ between lines $l_{1}$ and $l_{2}$ are computed by Equation 4

$$
\cos \alpha=\frac{a_{1} \cdot a_{2}+b_{1} \cdot b_{2}+c_{1} \cdot c_{2}}{\sqrt{a_{1}^{2}+b_{1}^{2}+c_{1}^{2}} \cdot \sqrt{a_{2}^{2}+b_{2}^{2}+c_{2}^{2}}}
$$

\section{RESULTS}

The camera was fixed on a station 2.5 meters away from treadmill for measuring the runner motion. Integration time was set to $30(3.3 \mathrm{~ms})$. The motion period is less than 2 seconds while the man was running on treadmill. The 280 frames (about 5 seconds) were recorded during the movements. Target shapes were located on the model before the measurement. The locations of the target on the body were decided according to angle that will be measured.

The intensity images were created for the frames. Then successive 10 frames that have covered the motion period were selected from the intensity images (Figure 5, Figure 6, Figure 7).
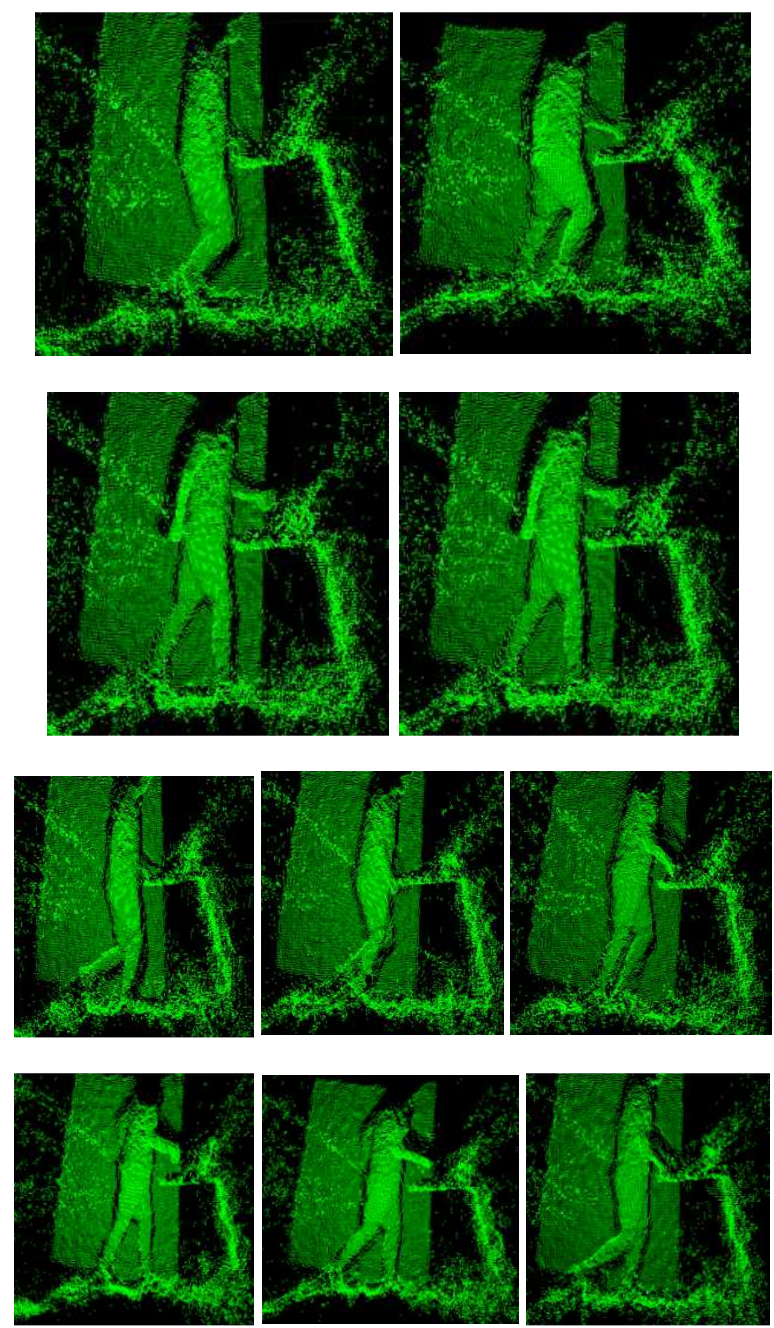

Figure 5. Point cloud data of selected frames
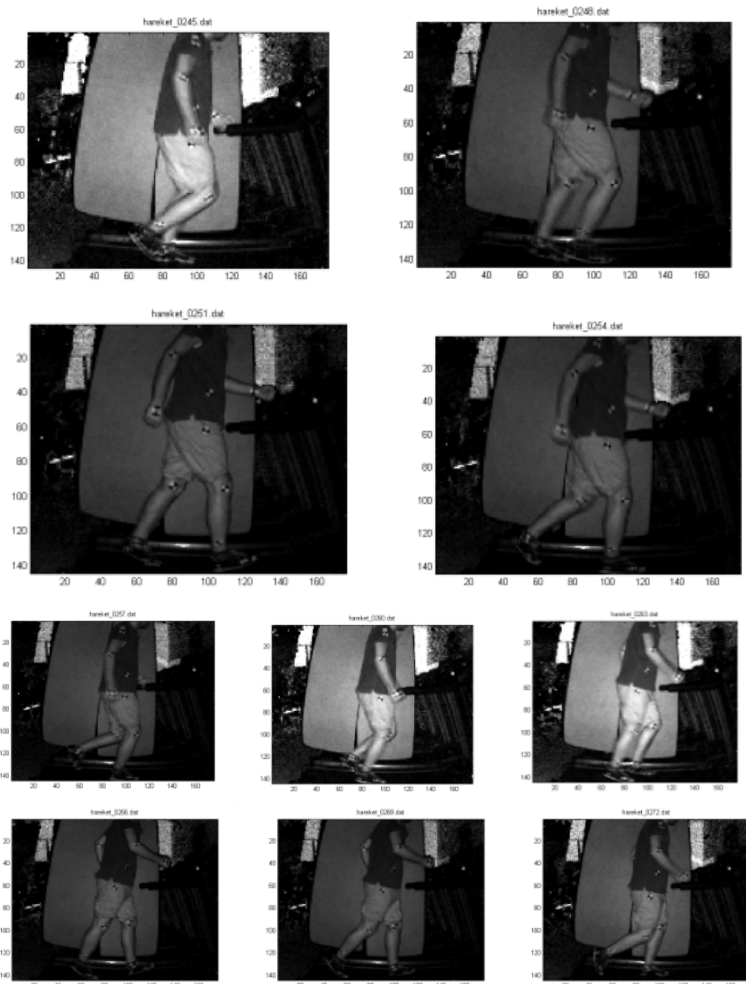

Figure 6. Intensity images of selected frames 

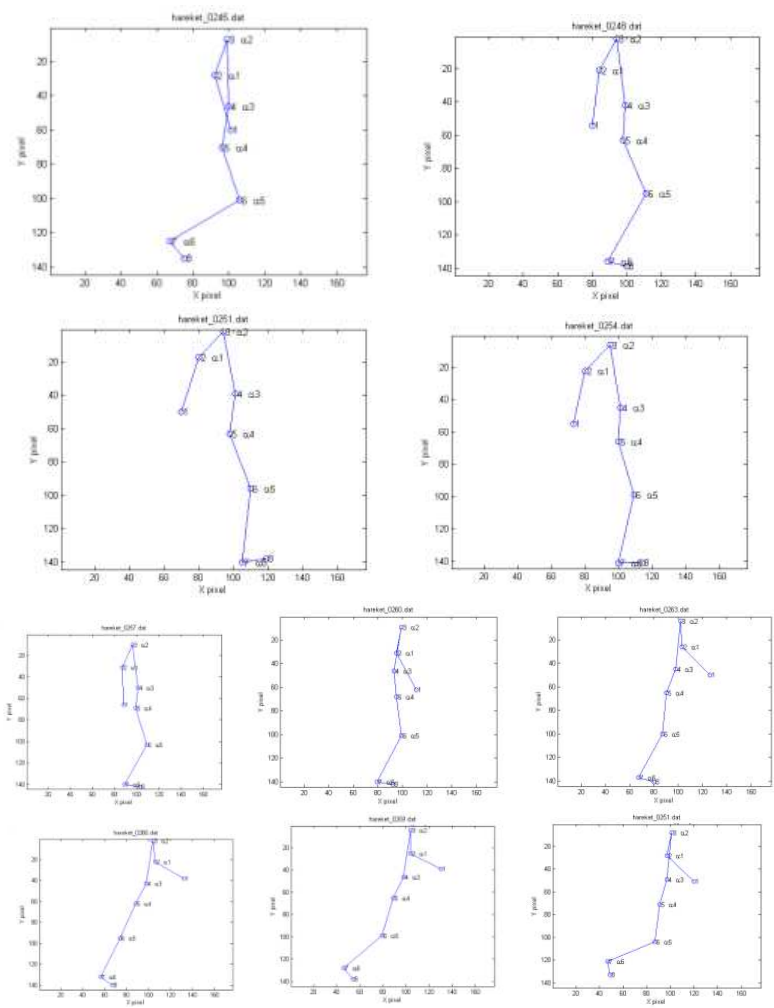

Figure 7. Angle positions on the selected successive frames

After the pixel coordinates of the targets were determined from the intensity images, their 3-D coordinates were extracted from the image files (Table 2). The 6 angles between the 7 lines were computed from selected frames by Eq.4 in 3-D space (Figure 7,
Figure 8 ). The variations on the angles during the motion are shown on Figure 9.

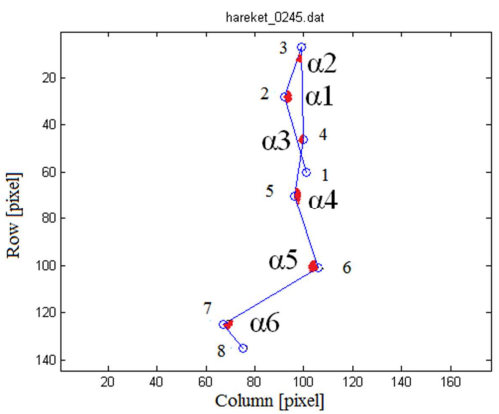

Figure 8. Target points and the angles on the first of consecutive frames

\begin{tabular}{|l|l|l|l|l|l|}
\hline \multirow{2}{*}{$\begin{array}{l}\text { Point } \\
\text { No }\end{array}$} & \multicolumn{3}{l|}{$\begin{array}{l}\text { Image } \\
\text { coordinates }\end{array}$} & \multicolumn{3}{l|}{ 3-D coordinates } \\
\cline { 2 - 6 } & Col & Row & $\mathrm{X}(\mathrm{m})$ & $\mathrm{Y}(\mathrm{m})$ & $\mathrm{Z}(\mathrm{m})$ \\
\hline 1 & 101 & 60 & -0.08 & 0.10 & 2.17 \\
\hline 2 & 92 & 28 & 0.00 & 0.37 & 2.07 \\
\hline 3 & 99 & 7 & -0.06 & 0.57 & 2.07 \\
\hline 4 & 100 & 46 & -0.07 & 0.23 & 2.26 \\
\hline 5 & 96 & 70 & -0.03 & 0.01 & 2.15 \\
\hline 6 & 106 & 101 & -0.13 & -0.28 & 2.28 \\
\hline 7 & 67 & 125 & 0.23 & -0.49 & 2.16 \\
\hline 8 & 75 & 135 & 0.17 & -0.62 & 2.29 \\
\hline
\end{tabular}

Table 2. Image and 3-D coordinates of the targets in the first image of the sequence

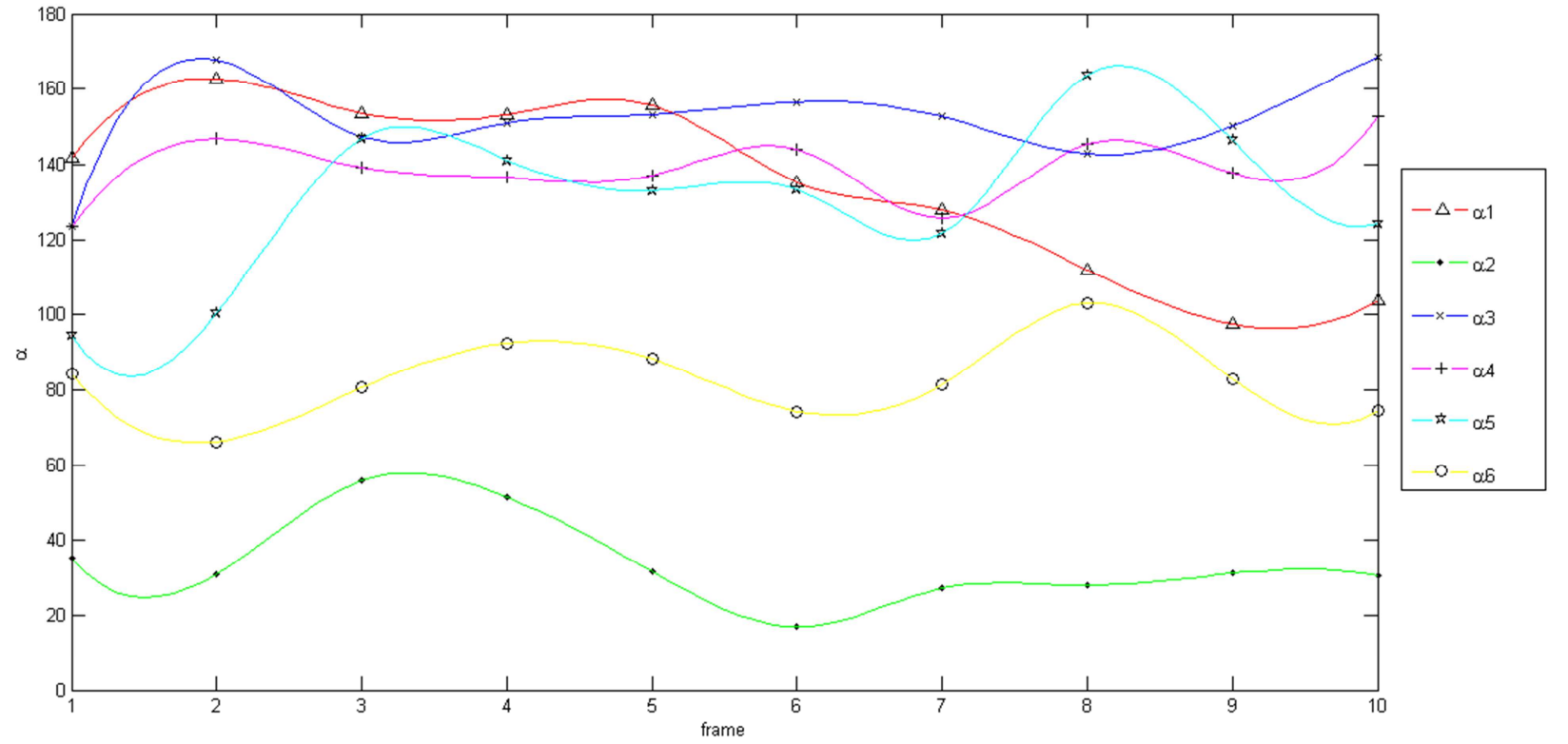

Figure 9 . The angles between the body parts during the motion

\section{CONCLUSIONS}

ToF camera is new technology in 3-D measurement. Its application areas have been ascended day by day thanks to its low cost and ability to repetitive and mobile measurement. Nevertheless, it has weak property like short measurement range and accuracies depended surface reflectivity. Even then, it is proper instrument for modelling, robotics and motion 
detection at indoor environment. In this study it has been used for measurement of body motion on treadmill. The angles during the movement were computed from the consecutive frames. The result show the human motion can be analysed from $\mathrm{ToF}$ camera images.

\section{REFERENCES}

Altuntas, C., Yildiz, F., 2013. The registration of point cloud data from range imaging camera, Geodesy and Cartography, 39(3), pp. 106-112.

Altuntaş, C., 2014. Lazerli ölçme kameralarının teknik özellikleri ve SR4000 ve CamBoard nano kamera ölçü sonuçlarının değerlendirilmesi. Harita Dergisi, Sayı 151, pp. 19-32.

Beringe, A.V., 2012. Performance evaluation of a range camera SR4000. Diplomarbeit, Ausgeführt am Institut für Photogrammetrie und Fernerkundung der Technischen Universitat Wien.

Boehm, J., Pattinson, T., 2010. Accuracy of exterior orientation for a range camera. In: The International Archives of the Photogrammetry, Remote Sensing and Spatial Information Sciences, Newcastle upon Tyne, UK, Vol. XXXVIII, Part 5, pp. 103-108.

Breuer, P., Eckes, C., Muller, S., 2007. Hand gesture recognition with a novel IR time-of-flight range camera-A pilot study. A. Gagalowicz and W. Philips (Eds.): MIRAGE 2007, LNCS 4418, pp. 247-260.

Cazorla, M., Viejo, D., Pomares, C., 2010. Study of the SR4000 camera. Proceeding XI Workshop of Physical Agents Físicos, Valencia, Spain, http://www.jopha.net/waf/ index.php/waf/waf10/paper/viewFile/83/61 (15 April, 2016).

Clemente, L., Davison, A., Reid, I., Neira J., Tardos, J.D., 2007. Mapping large loops with a single hand-held camera. Proceding of Robotics: Science and Systems Conference, Atlanta, GA, USA, http://www.roboticsproceedings.org/ rss03/p38.html (15 April, 2016).

Cui, Y., Schuon, S., Chan, D., Thrun, S., Theobalt, C., 2010. 3D shape scanning with a time-of-flight camera. IEEE conference on Computer Vision and Pattern Recognition, San Francisco, CA, DOI: 10.1109/CVPR.2010.5540082, pp. 1173-1180.

Frank, B. Schmedding, R., Stachniss, C., Teschner, M., Burgard, W., 2010. Learning the elasticity parameters of deformable objects with a manipulation robot. Procedings. of the IEEE/RSJ International Conference on Intelligent Robots and Systems (IROS), Taipei, Taiwan, DOI: 10.1109/IROS.2010.5653949, pp.1877-1883.

Ganapathi, V., Plagemann, C., Koller, D., Thrun, S., 2010. Real time motion capture using a single time-of-flight camera. IEEE Conference on Computer Vision and Pattern Recognition (CVPR), San Francisco, CA, DOI: 10.1109/CVPR.2010.5540141, pp. 755-762.

Hussmann, S., Ringbeck, T., Hagebeuker, B., 2008. A performance review of $3 \mathrm{D}$ ToF vision systems in comparison to stereo vision systems. Stereo Vision, Ed.by Asim Bhatti, ITech, Vienna, Austria, http://www.intechopen.com/books/stereo_vision/a_performance _review_of_3d_tof_vision_systems_in_comparison_to_stereo_ vision_systems (14 April, 2016).

Jamtsho, S., 2010. Geometric modelling of 3D range cameras and their application for structural deformation measurement. Master Sciences Thesis, Department of Geomatics Engineering, Calgary, Alberta.

Kahlmann, T., Remondino, F., Ingensand, H., 2006. Calibration for increased accuracy of the range imaging camera Swissranger TM. In: The International Archives of the Photogrammetry, Remote Sensing and Spatial Information Sciences, Dresden, Germany, Vol. XXXVI, Part 5, pp. 136-141.

Lahamy, H., Lichti, D.D., 2011. Evaluation of real-time hand motion tracking using a range camera and the mean-shift algorithm. In: The International Archives of the Photogrammetry, Remote Sensing and Spatial Information Sciences, Calgary, Canada, Vol. XXXVIII Part 5/W12, pp. 139144.

Lahamy, H. Lichti, D.D., 2012. Towards real-time and rotationinvariant American sign language alphabet recognition using a range camera. Sensors, 12 (11), pp. 14416-14441.

Lichti, D.D., Qi, X., 2012. Range camera self-calibration with independent object space scale observations. Journal of Spatial Sciences, 57(2), pp. 247-257.

Lichti, D.D., S. Jamtsho, S.I. El-Halawany, H. Lahamy, J. Chow. T.O. Chan, El-Badry, M., 2012. Structural deflection measurement with a range camera. ASCE Journal of Surveying Engineering. 138 (2), pp. 66-76.

Matzka, S., Petillot, Y.R., Wallace, A.M., 2007. Fast motion estimation on range image sequences acquired with time a 3-d camera, Proceedings of the Britisch Machine Vision Conference (BMVC), University of Warwick, UK, doi:10.5244/C.21.82

Mesa Imaging, 2012. SR4000 User Manuel, Version 1.4.

Moeslund, T. B., Hilton, A., Kruger. V., 2006. A survey of advances in vision-based human motion capture and analysis. Computer Vision and Image Understanding, 104(2-3), pp. 90126.

Oggier, T., Büttgen, B., Lustengerber, F., 2005. Swissranger SR3000 and first experiences based on miniaturized 3d-ToF cameras. ETH 1st RIM Days. http://citeseerx.ist.psu.edu/ viewdoc/download?doi=10.1.1.330.1909\&rep=rep1\&type=pdf (15 April, 2016)

Piatti, D., 2010. Time-of-Flight Cameras: Tests, calibration and multi frame registration for automatic 3D object reconstruction. $\mathrm{PhD}$ Thesis, Politecnico di Torino Doctoral school of Environment and Territory, Italy.

Piatti, D., Rinaudo, F., 2012. SR-4000 and CamCube3.0 time of flight (ToF) cameras: tests and comparison. Remote Sensing, 4(4), pp. 1069-1089.

Pirker, K., Rüther, M., Bischof, H., 2010. An omnidirectional time-of-flight camera and its application to indoor SLAM. 11th Int. Conf. Control, Automation, Robotics and Vision, Singapore, DOI: 10.1109/ICARCV.2010.5707286, pp. 988-993.

Plagemann, C., Ganapathi, V., Koller, D., Thrun, S., 2010. Realtime identification and localization of body parts from depth images. IEEE International Conference on Robotics and 
Automation (ICRA), Anchorage, Alaska, USA, DOI: 10.1109/ROBOT.2010.5509559, pp. 3108-3113.

Shahbazi, M., Homayouni, S., Saadatseresht, M., Sattari, M., 2011. Range camera self-calibration based on integrated bundle adjustment via joint setup with a 2D digital camera. Sensors, 11(9), pp. 8721-8740.
Teizer, J., 2008. 3D range imaging camera sensing for active safety in construction. ITcon, vol. 13, pp. 103-117.

url-1: Heptagon. http://www.mesa-imaging.ch/home/ (accessed 9 April 2015) 